\title{
CARE AND FLOW
}

\section{USING SOFT SySTEMS METHODOLOGY TO UNDERSTAND TENSIONS IN THE PATIENT DISCHARGE PROCESS}

\section{Michael Emes ${ }^{1,}{ }^{*}$, Stella Smith ${ }^{2}$, Suzanne Ward ${ }^{3}$, Alan Smith ${ }^{1}$, Timothy Ming ${ }^{4}$}

1UCL Centre for Systems Engineering, 3 Taviton St, London, UK, WC1H 0BT, m.emes@ucl.ac.uk, ${ }^{2}$ Social Care Programme, NHS Digital, London, UK, stella.smith3@nhs.net, ${ }^{3}$ Occupational Therapy, NHS Foundation Trust, Surrey, UK, suzanneward@nhs.net, ${ }^{4}$ University of Bath, timming1992@gmail.com

*Author to whom correspondence should be addressed

This is a post-peer-review, pre-copyedit version of an article published in Health Systems. The definitive publisherauthenticated version is available online at: https://link.springer.com/article/10.1057/s41306-017-0027-6

\begin{abstract}
Many hospitals face a daily struggle to manage capacity, especially where wards contain patients with a combination of health and social care needs. In this study, Soft Systems Methodology was used to understand the process of discharging patients from an acute hospital and to answer the question 'Why do patients with complex needs often spend longer on the wards than is necessary?'. Through a series of twenty structured interviews, several problems with the discharge planning process were identified. Problems included ineffective communication, slow processing of paperwork, limited forward planning, no clear ownership of the process and delays in finding care in the community. The persistence of these problems despite longstanding guidance on discharge planning can be understood by recognising the tension between two different philosophies in hospitals - a traditional 'Care' mindset focusing on the immediate needs of patients on the wards, and a planning-focused 'Flow' mentality, where the hospital's responsibility to the wider community dominates. Soft Systems Methodology was found to be an effective approach for discussing discharge planning and highlighting this tension. Based on the insights gained from the interviews, three practical initiatives have now been implemented to reconcile the tension and thereby reduce delays in the hospital.
\end{abstract}

Keywords: Patient discharge process, Soft Systems Methodology, complex needs

\section{INTRODUCTION}

Achieving timely discharge of patients to free up beds has been a concern of acute hospitals for a long time (National Health Service and Community Care Act, 1990, Taraborrelli et al., 1998). The drive towards shorter lengths of stay means not only that treatment must be provided with minimal delay but also that the time available for discharge planning is reduced (Department of Health, 2010: 4). Over 80\% of patients that are discharged from hospital have quite well-understood needs that do not require significant planning: these are classified as simple discharges (Department of health, 2004). For the remaining patients - those with 'complex needs' - achieving safe and timely discharge can be challenging. Patients with complex needs require a combination of interventions from multiple practitioners spanning healthcare and social care, both before and after discharge from hospital. Premature discharge risks readmission (with the patient unprepared for a return home) or may lead to costlier social care services such as intensive home care. Delayed discharge, on the other hand, exposes the patient to greater risk of infection, contributes to dependence (both physical and psychological), and may consume unnecessary resources (Department of Health, 2010). Problems with the current discharge processes have been well documented such as by Bauer et al (2009). Previous studies have not adequately explored practitioners' perceptions of the discharge process, however; neither can they explain why problems persist in the face of longstanding guidance from the Department of Health $(2003,2004,2010)$. 
Between October 2012 and October 2013, a study of the discharge process was conducted at a major acute hospital in Surrey, UK ('the hospital'). The objective of this project was to investigate the discharge process and recommend interventions that would improve the effectiveness of the process, especially for patients with complex needs. Based on initial discussions with managers at the hospital, the authors developed the hypothesis that problems with the discharge process were rooted not only in objective challenges such as resource shortages and inefficient processes, but also in underlying differences of opinion as to how the processes should be applied. Given that multiple, possibly contradictory perspectives of the process were believed to exist, a systems thinking approach called Soft Systems Methodology (SSM) was used (Checkland, 1999). This enabled the authors to capture the views of staff involved in discharge planning through structured interviews, and to analyse the findings as part of a well-defined process. Our findings are broadly consistent with another study that used SSM to investigate discharge planning (Mukotekwa \& Carson, 2007), but we considered a broader range of stakeholders and went further in our conclusions. We suggest that failure to manage the inherent conflict between caring for patients (local view) and maintaining the flow of patients through the hospital (global view) hampers attempts to improve discharge planning. Whilst there are similarities in the perceived shortcomings of discharge planning, none of these previous studies explicitly addressed the conflicting opinions on responsibility for discharge planning or the different perceptions of the tension between care of the patient and maintaining patient flow.

The contributions of this paper are as follows. Firstly, we have provided further insights into practitioners' perceptions of discharge planning. Secondly, we have highlighted a specific tension between the manufacturinglike mindset of maximising throughput of the system and the caring mindset of looking after vulnerable patients (showing that this tension is recognised by all roles involved in discharge planning). Thirdly, we have provided a case study supporting the usefulness of SSM for understanding the process of discharging patients from acute hospitals and have discussed our findings in the context of psychology's dual process theories. Finally, we have proposed three practical recommendations for improving discharge planning, namely (i) more proactive identification at the hospital front door of patients with complex needs (ii) daily situation reports to discuss patient progress involving a multi-disciplinary team with clear leadership, and (iii) simplifying the paperwork necessary before patients with complex needs can be discharged.

The remainder of this paper is organised as follows. The next section explores the relevant literature including what is known about discharge planning and what research has been done using SSM. The detailed case study in the application of SSM is then described, followed by a discussion of the results and conclusions. The questions asked of interviewees are listed in an appendix.

\section{RELEVANT LITERATURE}

\section{DISCHARGE PLANNING}

The process of discharging patients from acute hospitals has long been recognised as challenging and various guidance documents have been developed to understand the process and improve performance (National Health Service and Community Care Act, 1990, Department of Health, 2003, National Audit Office, 2003, Department of Health, 2010). Various types of modelling have been used to explore the discharge process including Discrete Event Simulation, System Dynamics and Agent-Based Simulation (Lattimer et al., 2004, Khurma, 2009, Gunal, 2012, Khurma et al., 2013). Discrete event simulation in particular has been used to identify contributing factors for extended lengths of stay and corresponding strategies for bed management (Millard, 1993, El-Darzi et al., 1998, Millard et al., 2000, Katsaliaki et al., 2005). Other studies have taken a more participative approach for engaging with stakeholders, such as interviewing health and social care practitioners, conducting focus groups and work shadowing. Some of these studies have explicitly applied systems thinking, or a 'whole system approach' to thinking about discharge planning (Health \& Social Care Joint Unit and Change Agents Team, 2003, Mukotekwa \& Carson, 2007, Kotiadis et al., 2014).

From previous literature, it is known that good discharge planning from acute hospitals requires clear communication and input from a broad range of practitioners, including Doctors, Nurses, Occupational 
Therapists, Physiotherapists, Social Care Practitioners and Discharge Coordinators (Bull, 1994). It is also known that elderly patients require "more complex care on discharge from an acute care facility" (Bauer et al., 2009: 2541). Particularly for these patients with complex needs, ineffective communication is a barrier to achieving a timely discharge: "hospital discharge planning for frail older people can be improved if interventions address family inclusion and education, communication between health care workers and family, interdisciplinary communication and ongoing support after discharge" (Bauer et al., 2009: 2539). Naylor et al (1999) investigated the effectiveness of nurse-led comprehensive discharge planning and home follow up for hospitalised older people, and found that this reduces readmissions and decreases the costs of providing health care relative to patients that receive routine discharge planning. Bull and Roberts (2001) found proper discharges to be highly multi-disciplinary, including the stages:(i) getting to know the patient, (ii) identifying initial discharge plans, (iii) getting the patient ready to go home and (iv) assessing older adults' transition back to the community. Forward planning is sometimes lacking even though many interventions should commence well before discharge (Bauer et al., 2009). This is particularly true for patients who might be medically fit to leave hospital quite soon after admission, since with a low length of stay there may be insufficient time for practitioners to understand a patient's needs and develop a discharge plan to suit the patient's circumstances (Cummings \& Cockerham, 1997, Cummings, 1999, Payne et al., 2002, Maramba et al., 2004). A Cochrane review of 24 studies into the effects of individualised discharge plans concluded that "a structured discharge plan tailored to the individual patient probably brings about a reduction in hospital length of stay and readmission rates" (Shepperd et al., 2003: 2). A more recent study across 30 trials involving 11964 patients found that discharge plans tailored to an individual led to an average reduction of 0.73 days in length of stay (Gonçalves-Bradley et al., 2016). Good planning is particularly important to achieve timely access to post-acute care services such as care homes, which have limited capacity (Katsaliaki et al., 2005).

Despite the long recognised challenges in discharge planning and the existence of guidelines to help improve performance (National Audit Office, 2003), the problem persists, and new guidelines continue to be developed. The UK Department of Health has issued guidance on planning for discharge as part of its 'Building a Society for all ages' strategy. This guidance outlines ten key steps to achieve safe and timely discharge (Department of Health, 2010). We have grouped the ten steps into three broad themes in Table 1. These themes are reflected upon in the context of our findings in the Conclusions section. The high complexity of healthcare decision making is well known; Gawande has written of the value of checklists in improving performance in these situations (Gawande, 2011). Whilst checklists are already used in the hospital for decision making regarding discharge, however, they apply only for part of the process and for a small subset of patients with a particular set of social care needs. A checklist for the whole discharge process would be a valuable decision aid, although it would itself need to be quite sophisticated to cover the range of circumstances encountered in the patient journey.

\begin{tabular}{|c|c|}
\hline Theme & Description \\
\hline Proactivity & $\begin{array}{l}\text { Planning for discharge should start on or before admission, and practitioners should identify early } \\
\text { those patients with complex needs. A clinical management plan should be developed for each patient } \\
\text { within } 24 \text { hours of admission, with an expected date of discharge within } 24 \text { to } 48 \text { hours of admission. }\end{array}$ \\
\hline $\begin{array}{l}\text { Effective } \\
\text { communication }\end{array}$ & $\begin{array}{l}\text { Discharge should be coordinated through effective leadership and handover of responsibilities, with the } \\
\text { clinical management plan reviewed with the patient and carers each day. }\end{array}$ \\
\hline $\begin{array}{l}\text { Keeping the } \\
\text { process moving }\end{array}$ & $\begin{array}{l}\text { Decisions to discharge should be made each day, with discharges planned to take place over seven days } \\
\text { and a checklist used } 24-48 \text { hours before discharge to make sure everything's in place. Although simple } \\
\text { checklists may be useful, it is also recognised by some studies that much of the paperwork for discharge } \\
\text { planning is overly complex. This not only delays discharge but also reduces the sense of professionalism } \\
\text { of staff (Connelly et al., 2009). }\end{array}$ \\
\hline
\end{tabular}

TABLE 1: SUMMARY OF DEPARTMENT OF HEALTH (2010) GUIDANCE

\section{Problem Structuring Methods}

There has been a growing recognition of the complexity of healthcare decision making like discharge planning, where every intervention "has an effect on the overall system, and the overall system has an effect on every intervention" (WHO, 2009: 19). Cause and effect between care interventions and results are never straightforward but complex and dynamic (Brailsford et al., 2004). Where different stakeholders disagree on the 
specific objectives of a process or system, traditional deterministic postpositivist research methods that seek to identify an objective underlying truth are of limited effectiveness (Checkland, 1999, Creswell, 2014). Instead, systems thinking is particularly important (Audit Commission, 2002) and is already recognised at government level for healthcare management (Health \& Social Care Joint Unit and Change Agents Team, 2003). Indeed, previous UK Department of Health guidelines have identified 'developing a whole system approach' as a foundation of their policy for improving discharge planning (Department of Health, 2003). In dealing with complex situations, 'soft' operational research techniques or Problem Structuring Methods (PSMs) are applicable. The most popular of these (Rosenhead, 1996) are SSM, Strategic Options Development and Analysis (SODA) and the Strategic Choice Approach (SCA).

SODA is a workshop-based method that uses cognitive mapping to elicit and record participants' views of a problem situation, where a facilitator ultimately guides the group to commit to a number of actions (Eden, 1989, Rosenhead, 1996). In SCA, facilitators assist participants to model the interconnectedness of decision areas. Four modes of strategic choice exist - shaping, designing, comparing and choosing. Through interactive workshops, alternative decision options are compared and key uncertainties identified. These uncertainties may concern the working environment, guiding values or related choices. From these, priority areas for interventions are developed (Friend \& Hickling, 1987, Rosenhead, 1996). Checkland (1999: 318) defines SSM as a "systems-based methodology for tackling real-world problems in which known-to-be-desirable ends cannot be taken as given. In contrast to 'hard' systems engineering in which the objective to be achieved and approach to optimisation are clearly agreed in advance, Soft Systems Methodology is based upon a phenomenological stance", where human perception and interpretation are taken to influence reality (Checkland, 1999, Checkland \& Scholes, 1999, Jackson, 2000, Wilson, 2001, Checkland \& Poulter, 2006, Checkland, 2012). Starting with a problematic situation that is the focus of the investigation, a number of interpretations of what's going on in the situation are identified ('purposeful activity systems') with corresponding philosophies or 'worldviews'. These purposeful activity systems are used to generate conceptual models, which through comparison with the real world are used to identify possible improvements. Checkland's original approach to SSM consists of a seven-stage process:

1. Situation considered problematical

2. Problem situation expressed

3. Definitions of relevant purposeful activity systems

4. Conceptual models of the relevant systems named in the definitions

5. Comparison of models and real world

6. Changes: systemically desirable and culturally feasible

7. Action to improve the problem situation

Here, steps 1, 2, 5, 6 and 7 involve analysis in the real world, whilst steps 3 and 4 involve systems thinking about the real world, building models and abstractions that help our understanding. Note that the output of stage 3 is a number of 'root definitions' of the purposeful activity systems. A simplified four-stage version of this process has also been developed (Checkland \& Scholes, 1999), where steps 1 and 2 are combined into 'finding out about the problem situation', stages 3 and 4 become 'formulating some relevant purposeful activity models', stages 5 and 6 together become 'debating the situation' and stage 7 remains the same, i.e. 'taking action to improve the situation'. Each root definition expresses the essence of the system, conventionally in a single long sentence, capturing six different aspects that are commonly remembered by SSM practitioners using the CATWOE mnemonic as shown in Table 2.

\begin{tabular}{|l|l|}
\hline Role & Description \\
\hline Customers & The beneficiaries (or in some cases victims) of the transformation. \\
\hline Actors & Those agents responsible for effecting the transformation \\
\hline Transformation & $\begin{array}{l}\text { The proposed or observed change that is the focus of the soft systems analysis. This can be thought of } \\
\text { as a change of state that occurs between the start and end of the process under investigation }\end{array}$ \\
\hline Worldview & $\begin{array}{l}\text { The beliefs directly relevant to the transformation that explain its purpose. The worldview is a belief } \\
\text { that, although not explicitly stated in the root definition, must be true in order for the root definition to }\end{array}$ \\
\hline
\end{tabular}




\begin{tabular}{|l|l|}
\hline & $\begin{array}{l}\text { make sense (Wilson, 2001: 22). A previous study (Emes et al., 2012), explains that worldviews may } \\
\text { contain two levels of belief: } \\
\text { W1 ('how?' worldview) - the belief that the method of conducting the transformation is effective } \\
\text { and efficient } \\
\text { W2 ('why?' worldview) - the belief that the transformation is an effective and efficient way to } \\
\text { enable the higher level objective to be achieved }\end{array}$ \\
\hline $\begin{array}{l}\text { Owners } \\
\text { Environmental } \\
\text { constraints }\end{array}$ & $\begin{array}{l}\text { Those responsible for the outcomes of the process and with the power to change or stop it } \\
\text { environment that are taken as given }\end{array}$ \\
\hline
\end{tabular}

TABLE 2: ENRICHING ROOT DEFINITIONS USING 'CATWOE'

Whilst all three of the PSMs described above can be used to explore different opinions qualitatively through a constructivist mode of inquiry, both SODA and SCA require significant workshop activities involving multiple participants at once to develop the insights. With a large number of stakeholders identified for the current study, the authors and sponsors of the project felt that the main part of the research should occur through one to one interviews. One of the authors already had experience of applying Checkland's seven-stage process for SSM in a similar study in another domain (Emes et al., 2012), and felt SSM would be an appropriate method for this research.

\section{USING SSM FOR HEALTHCARE}

There are many previous examples of the application of SSM in healthcare as shown in Table 3. Although Connell's (2013) case study reports mixed results on the effectiveness of SSM (with some issues experienced in the implementation of the interventions), most of the literature reports positive outcomes.

The authors are aware of only one study where SSM has been used with a focus on the patient discharge process: Mukotekwa and Carson (2007). This focused on nurse-led discharge planning, with relatively little consideration of the viewpoints and priorities of other health and social care practitioners. They identified two conceptual models, one focusing on quality and continuity of care, the other focusing on resource use, concluding that discharge planning could be improved through greater co-operation and communication between healthcare professionals, and the adoption of a more holistic approach to patient needs by nurses (Mukotekwa \& Carson, 2007: 685).

\begin{tabular}{|l|l|}
\hline Author (s) & Studies \\
\hline Baldwin et al. (2004) & Simulation in healthcare management \\
\hline Checkland and Poulter (1994) & Production of a hospital information and systems strategy \\
\hline Checkland and Scholes (1999) & $\begin{array}{l}\text { East Berkshire Community Medicine Department - performance measurement and } \\
\text { improvement }\end{array}$ \\
\hline Connell (2013) & $\begin{array}{l}\text { Design of an information system for health service users providing care in the } \\
\text { community }\end{array}$ \\
\hline Esain et al. (2012) & Quality improvement initiatives across NHS England healthcare trusts \\
\hline Kalim et al. (2004) & Healthcare policy provision and decision support \\
\hline Kotiadis et al. (2013) & Modelling performance measures in SSM \\
\hline Kotiadis et al. (2014) & Conceptual modelling for discrete event simulation in healthcare \\
\hline Lehaney and Paul (1996) & Development of a Simulation of Out-Patient Services at Watford General Hospital \\
\hline Mukotekwa and Carson (2007) & Improving the discharge planning process \\
\hline Rose and Haynes (1999) & Evaluation of Complex Interventions in the Public Sector \\
\hline Wells (1995) & An analysis of nurse management and activity on a psychiatric in-patient facility \\
\hline
\end{tabular}

TABLE 3: PREVIOUS STUDIES USING SOFT SYSTEMS METHODOLOGY IN HEALTHCARE

Our study confirms some of the findings of Mukotekwa and Carson (2007) including the value of greater coordination between health and social care practitioners. However, we go further by incorporating the views of additional important stakeholders - Registrars, Consultants and Discharge Coordinators - and also by investigating how different stakeholders may subscribe to different philosophies. We also highlight a barrier to improving discharge planning, namely, the tension between two worldviews: the need to provide timely 
treatment to those in need on the wards, and the need to plan ahead to provide an effective and efficient service for the wider community.

\section{CASE STUDY}

The approach and results from each of the seven stages are explained below.

\section{STAGE 1: THE SITUATION CONSIDERED PROBLEMATICAL}

Through initial discussions with managers in occupational therapy (OT) and social care (the main points of contact for the project), it was identified that there were often delays in discharging patients from the hospital, especially for patients with a combination of health and social care needs. There were many individuals involved in the discharge process, and despite regular multi-disciplinary team (MDT) meetings there were tensions between healthcare practitioners and social care in terms of responsibility for delaying patients' discharge. Regular 'PANDA' (Patients After Nine Days from Admission) meetings were held and there was a culture at these meetings of looking to identify the people responsible for causing delays rather than focusing on expediting individual patients' progress or improving the discharge process in general. Documentation necessary to discharge patients with complex needs was not completed in a timely fashion (in particular the Health Needs Assessment ${ }^{1}$ ) and the different practitioners involved in managing a patient's discharge did not share information effectively.

\section{STAGE 2: THE PROBLEM SITUATION EXPRESSED}

Through the initial discussions with managers, the authors recognised that the patient was at the heart of a complex web of relationships.

We summarised the (explicit or implicit) attitudes of the different actors involved in the discharge process using the rich picture shown in Figure 1. The arrows in the figure indicate influences. The rich picture captured our initial understanding of the key viewpoints and tensions developing in the context of the patient discharge process. Although there was a document explaining to patients what to expect as far as their discharge from hospital was concerned, there was no common, formalised process for staff explaining roles and responsibilities; each practitioner had his or her own view of the process.

To explore the problem situation, twenty structured interviews were conducted with staff at the hospital focusing on two care of the elderly wards where many patients have complex needs. Following development of the rich picture (Figure 1), suitable interviewees were identified in discussion with hospital managers, covering the roles of: Nurse, Ward Sister, Consultant, Registrar, Transport Coordinator, Occupational Therapist, Occupational Therapy Manager, Physiotherapist, Social Care Practitioner, Social Care Manager, Discharge Coordinator, Medical Director, Patient Experience Representative, Rapid Response Nurse and Rapid Response Occupational Therapist. Each interview lasted for approximately an hour. The interviewees were asked the questions shown in the Appendix. Each interview was conducted by two of the authors (Emes and Ming) and was recorded, with detailed notes also taken. The transcripts were sent to the interviewees for review and then modified appropriately.

\footnotetext{
1 The Health Needs Assessment (HNA) is a document produced to summarise a patient's health care needs at a point in time. This pulls together inputs from several different practitioners, and has been used by local government as a first step in determining the source of funding for a patient's continuing healthcare.
} 


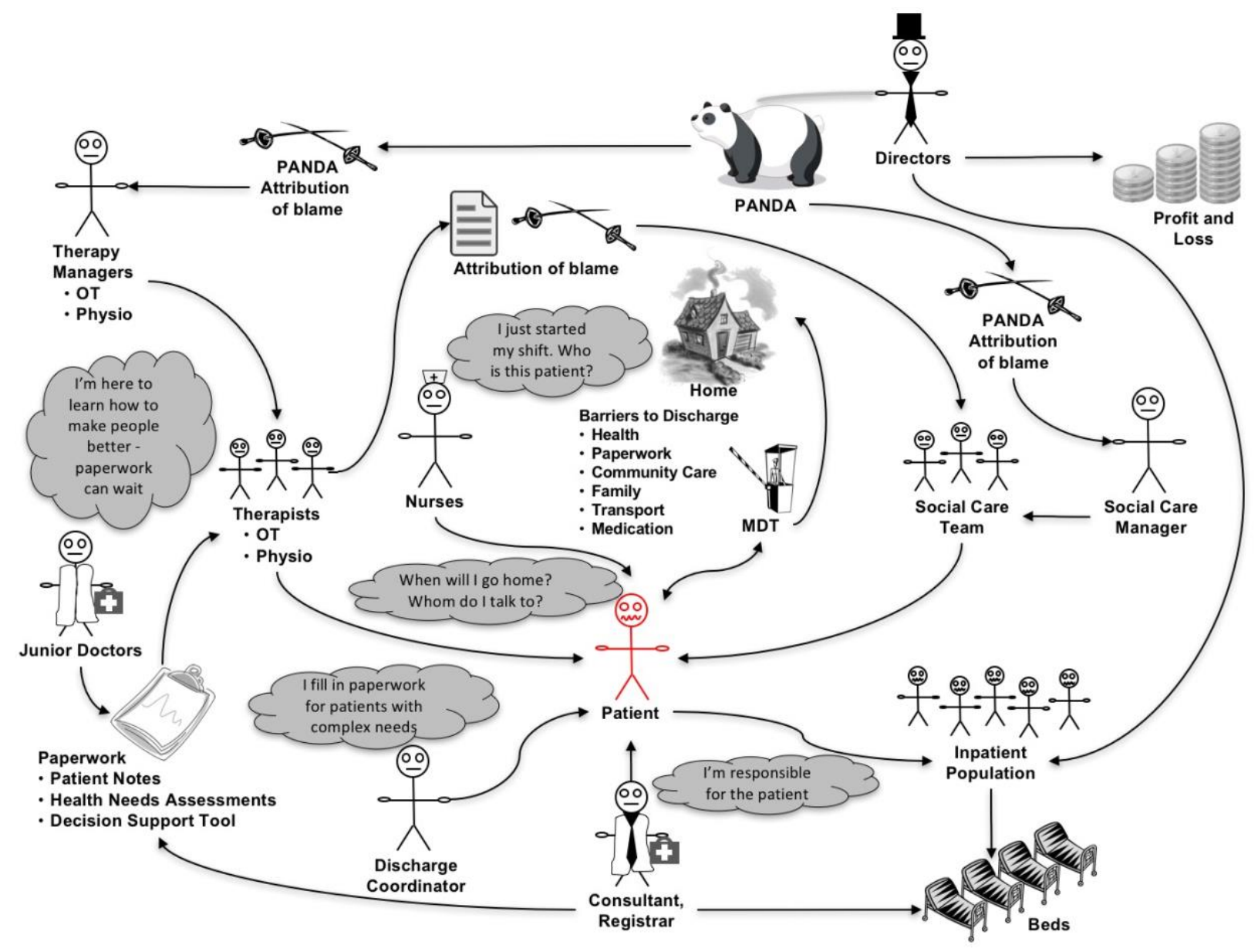

FIGURE 1: RICH PICTURE OF PROBLEM SITUATION UNDER INVESTIGATION

Interviewing a broad cross-section of patients or their families was impractical within the scope of the project. Instead, previous data captured from patient experiences on discharge were referred to. As part of another project at the hospital investigating delays at the very end of the discharge process, five patients were interviewed on a respiratory ward and an orthopaedics ward in the period 13-20 January 2012 to investigate their experience of the discharge process. All of these patients were approached on the day of discharge and were asked to share their general experiences. Patient responses fell under the headings of 'Estimated date of discharge', 'Patient lounge', 'Perceived delay in discharge', 'Transportation home' and 'General perceptions on the discharge process'. Anonymous information from these interviews informed the root definitions and conceptual models developed in this study.

\section{INTERVIEW FINDINGS}

The common views that were generally held by most or all participants are summarised in Table 4 .

\begin{tabular}{|l|l|l|}
\hline Theme & Summary of findings & Supporting literature \\
\hline Beneficiaries & $\begin{array}{l}\text { The main beneficiaries of the discharge process are patients } \\
\text { and their families (rather than the hospital or the wider } \\
\text { community). }\end{array}$ & $\begin{array}{l}\text { Khurma (2009) suggests that } \\
\text { strategic planning aims to maximize } \\
\text { patient access and } \\
\text { flow to best meet the needs of } \\
\text { patients and their families. }\end{array}$ \\
\hline $\begin{array}{l}\text { Efficiency and } \\
\text { effectiveness } \\
\text { measures }\end{array}$ & $\begin{array}{l}\text { An effective discharge process is one in which patients are } \\
\text { discharged to appropriate destinations compatible with } \\
\text { their health and social needs in a timely way. Measures of } \\
\text { effectiveness include number of re-admissions (which might } \\
\text { indicate premature discharge or inappropriate support after } \\
\text { discharge) the average time between being declared }\end{array}$ & $\begin{array}{l}\text { The Mukotekwa and Carson (2007) } \\
\text { 676) definition of effective resource } \\
\text { utilisation includes "ensuring that } \\
\text { patients are referred and assessed by } \\
\text { the appropriate healthcare and } \\
\text { community professionals" and }\end{array}$ \\
\hline
\end{tabular}




\begin{tabular}{|c|c|c|}
\hline & $\begin{array}{l}\text { medically stable and discharge, and average length of stay. } \\
\text { An efficient discharge process is one that uses a minimum of } \\
\text { hospital and social care resources to achieve safe and timely } \\
\text { discharges to appropriate destinations. }\end{array}$ & $\begin{array}{l}\text { "effective co-ordination of the } \\
\text { process itself, taking care that } \\
\text { unnecessary delays are } \\
\text { avoided ... aiding this with good } \\
\text { communication, information } \\
\text { availability, decision making } \\
\text { and monitoring the flow of process". }\end{array}$ \\
\hline $\begin{array}{l}\text { Discharge decision } \\
\text { making }\end{array}$ & $\begin{array}{l}\text { MDTs take collective responsibility for the discharge of each } \\
\text { patient from the hospital - it is not an individual decision. } \\
\text { Consultants have the ultimate say on when a patient is fit to } \\
\text { be discharged and are often deferred to for decision-making. } \\
\text { Nurses welcome patients onto the ward and formally } \\
\text { discharge them from the ward. An Estimated Discharge Date } \\
\text { (EDD) is not provided for all patients upon admission, and } \\
\text { when they are used they are really 'earliest' discharge dates; } \\
\text { they are idealistic and almost always go backwards - almost } \\
\text { never come forwards. The social care team becomes } \\
\text { involved in enabling a safe discharge only after the medical } \\
\text { team declares a patient stable. When Discharge } \\
\text { Coordinators become involved for patients with complex } \\
\text { needs, it is often assumed by other practitioners that they } \\
\text { will manage the whole process. }\end{array}$ & $\begin{array}{l}\text { The prevalence of team-based } \\
\text { decision-making is reported in other } \\
\text { research such as Godfrey and } \\
\text { Townsend (2009). } \\
\text { The role of Discharge Coordinators as } \\
\text { enablers of seamless service } \\
\text { provision is described by Mukotekwa } \\
\text { and Carson (2007). }\end{array}$ \\
\hline Communication & $\begin{array}{l}\text { Sharing of information can be a problem - information on } \\
\text { the discharge process is not well communicated to patients } \\
\text { and families. Patients are asked the same questions by } \\
\text { different practitioners, which can irritate patients. Holding } \\
\text { daily MDT meetings helps to improve communication on the } \\
\text { ward, and may expedite the discharge process. }\end{array}$ & $\begin{array}{l}\text { Other studies also stress the } \\
\text { importance of good communication } \\
\text { between healthcare workers and } \\
\text { family, and effective interdisciplinary } \\
\text { communication (Bauer et al., 2009, } \\
\text { Department of Health, 2010). }\end{array}$ \\
\hline Sources of delay & $\begin{array}{l}\text { Patients often spend longer on the wards than is necessary. } \\
\text { Common sources of delays (once a patient is medically } \\
\text { stable), roughly ordered in terms of impact (highest first), } \\
\text { include waiting for paperwork to be completed (particularly } \\
\text { HNAs), waiting for availability of social care in the } \\
\text { community, families being unavailable or slow to make } \\
\text { decisions, patients and their families not agreeing with } \\
\text { social care staff on post discharge placement, waiting for } \\
\text { transport and waiting for medication to take out. }\end{array}$ & $\begin{array}{l}\text { Bauer et al (2009) find that hospital } \\
\text { discharge planning for frail older } \\
\text { people is delayed by lack of family } \\
\text { inclusion and education, poor } \\
\text { communication between healthcare } \\
\text { workers and family, inadequate } \\
\text { communication. Interventions should } \\
\text { commence well before discharge. }\end{array}$ \\
\hline
\end{tabular}

\section{TABLE 4: COMMON VIEWS GENERALLY HELD BY INTERVIEWEES}

As discussed in the right-hand column, the views described in Table 4 not only are shared by most of the interviewees in this study, but also are consistent with the findings of many other studies into the discharge process. The prevalence of multi-disciplinary decision making on discharge is clear. For patients with complex needs this is inevitable, as once a patient is recognised as having both health and social care needs, a discharge cannot occur until the patient is cleared by both a Doctor and a Social Care Practitioner. Whilst for these patients there is a perception amongst many practitioners that Discharge Coordinators manage the whole discharge process, there is a limited supply of Discharge Coordinators across the hospital. Decision making therefore often tends to be responsive rather than proactive, so patients may spend longer on the ward than is necessary.

A number of areas of inconsistency were identified in the interviews or 'divergent views' where views were expressed by only one or a few of the interviewees; in some cases, there were direct contradictions (Table 5).

\begin{tabular}{|l|l|l|}
\hline Theme & Summary of findings & Supporting literature \\
\hline $\begin{array}{l}\text { 'Medical model' of } \\
\text { care }\end{array}$ & $\begin{array}{l}\text { One therapist felt that consultant-led MDT meetings to } \\
\text { discuss patient progress towards discharge were strongly } \\
\text { focused on the medical factors and did not give much weight } \\
\text { to the wider social issues. On the other hand, a consultant } \\
\text { felt that the discharge process should benefit wider society }\end{array}$ & $\begin{array}{l}\text { The perceived dominance of the } \\
\text { medical model of care is a view } \\
\text { reported in other studies such as } \\
\text { Connelly et al. (2009). }\end{array}$ \\
\hline
\end{tabular}




\begin{tabular}{|c|c|c|}
\hline & not just the patients on the ward. & \\
\hline $\begin{array}{l}\text { Nurses shift } \\
\text { patterns }\end{array}$ & $\begin{array}{l}\text { There was tension over the shift patterns used by nurses } \\
\text { (three long days on, four days off). Nurses liked the shift } \\
\text { pattern and felt they had a good system for handing over } \\
\text { care between shifts, but other practitioners worried that it } \\
\text { might cause problems with continuity of care. }\end{array}$ & $\begin{array}{l}\text { This echoes a previous study that } \\
\text { found "nursing ward handover was } \\
\text { regarded as a process that hindered } \\
\text { communication. Lack of time was } \\
\text { reported to be the biggest barrier that } \\
\text { affected interprofessional working } \\
\text { and hence the co-ordination of } \\
\text { assessments" (Atwal, 2002: 450). }\end{array}$ \\
\hline $\begin{array}{l}\text { Responsibility for } \\
\text { managing } \\
\text { discharge }\end{array}$ & $\begin{array}{l}\text { The area with greatest divergence of views was around the } \\
\text { practical responsibility for managing the discharge of a } \\
\text { patient. A Consultant expressed the view that it was the } \\
\text { Consultant that implemented the process of discharging } \\
\text { patients, whereas a Sister felt that it was Nurses that } \\
\text { managed the process of discharging patients. An OT } \\
\text { explained that for patients with complex needs, Discharge } \\
\text { Coordinators managed the process, but for the "6 out of } 7 \\
\text { patients with straightforward needs", Discharge } \\
\text { Coordinators aren't involved and OTs take control. }\end{array}$ & $\begin{array}{l}\text { The view that nurses generally } \\
\text { manage the discharge process } \\
\text { reinforces findings of previous } \\
\text { literature (Watts \& Gardner, 2005, } \\
\text { Foust, 2007). }\end{array}$ \\
\hline $\begin{array}{l}\text { Understanding of } \\
\text { the discharge } \\
\text { process }\end{array}$ & $\begin{array}{l}\text { Consultants felt they had a clear idea of what needed to be } \\
\text { considered before discharge of elderly patients could occur } \\
\text { - a Comprehensive Geriatric Assessment - and believed that } \\
\text { there was a good understanding amongst the MDT members } \\
\text { of the general process that needed to be followed before } \\
\text { discharging a patient. Other MDT members did not have a } \\
\text { clear picture of the process. Some stated that discharge } \\
\text { planning started at the point of admission to the hospital. } \\
\text { The more general belief, however, was that discharge } \\
\text { planning started when the patient was declared medically } \\
\text { stable by the consultant }{ }^{2} \text {. }\end{array}$ & $\begin{array}{l}\text { Whilst Mukotekwa and Carson (2007) } \\
\text { did not highlight lack of } \\
\text { understanding of the discharge } \\
\text { process as an important factor, } \\
\text { Khurma (2009: 17) found that "there } \\
\text { is lack of understanding in the } \\
\text { sequence and structure of the } \\
\text { discharge process, which results in: } \\
\text { lack of consistency, hidden } \\
\text { inefficiencies, and difficultly in } \\
\text { analysing and improving the process". }\end{array}$ \\
\hline
\end{tabular}

TABLE 5: UNIQUE OR CONTRADICTORY VIEWS FROM INTERVIEWEES

Despite the general agreement amongst practitioners that discharge decision making was mainly executed through MDT meetings, it was very interesting to note that different roles had different views on which role was ultimately responsible for controlling the discharge process with Nurses, Consultants, Discharge Coordinators and Occupational Therapists all feeling that they had a leading role. There was no common vision of exactly what the discharge process involved, and no reference made to any official discharge policy. This reinforces the observation made in Table 5 that the interpretation of the discharge process was inconsistent across practitioners. Whilst many assume that group decision making is more effective than individual decision making (Salas et al., 2008), others have questioned the effectiveness of collective decision making in healthcare, highlighting the importance of effective leadership (Kaba et al., 2016).

Overall, the strongest messages that came from the interviewees (in no particular order) were (i) interviewees felt they knew what the discharge process was aiming to achieve, but felt that it wasn't implemented as well as it could be, (ii) communication between practitioners was inadequate, (iii) there was no clear ownership of the discharge process or responsibility for managing discharge (iv) the biggest sources of delay were paperwork and waiting for availability of social care in the community.

\section{STAGE 3: DEFINITIONS OF RELEVANT PURPOSEFUL ACTIVITY SYSTEMS}

\footnotetext{
2 When talking about patients with complex needs, practitioners often use the term medically stable to refer to those complex needs patients who no longer need to be kept in hospital on medical grounds. This may mean that they have returned to a baseline of health following an acute illness or injury, or that whilst they are still recovering they do not need to be in a hospital environment. It may also include palliative patients for whom hospital treatments will no longer be effective.
} 
The interview findings were used together with the authors' understanding of the process, to develop 'root definitions' of the system to discharge patients, generally in the form 'a system to ... do P by Q in order to achieve $\mathrm{R}^{\prime}$, in line with the conventional expression in SSM (Checkland, 1999, Wilson, 2001). These root definitions were elaborated by capturing information relating to the aspects shown in Table 2 during the interviews. In addition, the interviews captured information on the effectiveness of the discharge process (the extent to which it achieved its aims) and its efficiency (the extent to which it used resources economically). After the interviews were completed, the full set of views was analysed and discussed by the authors. From this process of reflection, two distinct root definitions emerged, each capturing a specific worldview or philosophy relating to the discharge process - a 'Care' philosophy and a 'Flow' philosophy. For each, a different concept of the process or system for discharging patients can be inferred.

\section{'CARE'}

The 'Care' philosophy is aligned with a model of patient care in which the medical team sees its primary responsibility as looking after vulnerable patients currently on the wards until such a time as they are recovered sufficiently to be safely returned home or placed into another care environment. The 'do P by Q in order to achieve $\mathrm{R}^{\prime}$ (the 'PQR') for this model is summarised in Table 6. Discharge planning in this model is not considered significantly until the patient is medically stable. The discharge process (i.e. the 'root definition' in SSM) can therefore be described as "a process conducted by the MDT to enable medically stable patients to leave the acute hospital environment when they are ready to go, by completing relevant paperwork and arranging transport, medication to take out, and any necessary care in the community, whilst providing ongoing care from medical practitioners, in order to ensure that patients on the wards receive the best possible care up to and beyond discharge from the acute hospital".

\begin{tabular}{|l|l|}
\hline Aspect & Description \\
\hline $\mathbf{P}$ & Enable medically stable patients to leave the acute hospital environment when they are ready to go \\
\hline $\mathbf{Q}$ & $\begin{array}{l}\ldots \text { by completing relevant paperwork and arranging transport, medication to take out, and any } \\
\text { necessary care in the community whilst providing ongoing care from medical practitioners }\end{array}$ \\
\hline $\mathbf{R}$ & $\begin{array}{l}\text {... to ensure that patients on the wards receive the best possible care up to and beyond discharge from } \\
\text { the acute hospital }\end{array}$ \\
\hline
\end{tabular}

TABLE 6: PQR FOR CARE MODEL

In this root definition, we can use the CATWOE mnemonic to identify the relevant roles/aspects as summarised in Table 7.

\begin{tabular}{|l|l|}
\hline Aspect & Description \\
\hline Customer & Medically stable patient \\
\hline Actor & $\begin{array}{l}\text { MDT consisting of Doctors, Nurses, Occupational Therapists, Physiotherapists, Social Care Practitioners } \\
\text { and Discharge Coordinators }\end{array}$ \\
\hline Transformation & $\begin{array}{l}\text { Medically stable patients receiving care in the hospital } \rightarrow \text { Medically stable patients no longer receiving } \\
\text { care within the hospital }\end{array}$ \\
\hline Worldview & $\begin{array}{l}\text { Keeping the patient in the safe hospital environment and starting discharge planning only when the } \\
\text { patient is medically stable avoids wasted practitioner time (since the patient's condition may change) } \\
\text { and minimises the risk of readmission }\end{array}$ \\
\hline Owner & MDT involving actors listed above \\
\hline $\begin{array}{l}\text { Environmental } \\
\text { constraints }\end{array}$ & Availability of beds and appropriately trained staff \\
\hline
\end{tabular}

TABLE 7: EXPLORING DIMENSIONS OF 'CARE' ROOT DEFINITION USING 'CATWOE'

\section{'FLOW'}

The 'Flow' philosophy is more like a production-line mindset: one in which the aim is to maintain the flow of patients through the system, identifying and removing any sources of delay. The PQR for the Flow model is shown in Table 8. 


\begin{tabular}{|l|l|}
\hline Aspect & Description \\
\hline $\mathbf{P}$ & Prepare patients admitted to the hospital for timely release from acute care \\
\hline $\mathbf{Q}$ & $\ldots$ by starting discharge planning and anticipating health and social care needs on admission to hospital \\
\hline $\mathbf{R}$ & $\begin{array}{l}\text {... to maintain the flow of patients through the hospital and maintain the hospital's capability to serve } \\
\text { the needs of the wider community }\end{array}$ \\
\hline
\end{tabular}

TABLE 8: PQR FOR FLOW MODEL

The discharge process in the Flow model can be defined ('root definition' in SSM) as: "A process to prepare patients admitted to the hospital to leave the hospital as early as possible (whilst suitably managing the risk of readmission) by starting discharge planning and anticipating health and social care needs on admission to hospital, conducted by Discharge Coordinators with input from Doctors, Nurses, Occupational Therapists, Physiotherapists and Social Care Practitioners, to ensure that patients stay in the hospital no longer than necessary, thereby freeing up capacity to serve the needs of the wider community." In this root definition, we can use the CATWOE mnemonic to identify the roles/aspects shown in Table 9:

\begin{tabular}{|l|l|}
\hline Aspect & Description \\
\hline Customer & Community of current and potential patients at the hospital \\
\hline Actor & $\begin{array}{l}\text { Discharge Coordinators supported by Doctors, Nurses, Occupational Therapists, Physiotherapists and } \\
\text { Social Care Practitioners }\end{array}$ \\
\hline Transformation & $\begin{array}{l}\text { Patients admitted to the hospital in need of acute care } \rightarrow \text { Patients outside the hospital no longer } \\
\text { needing acute care }\end{array}$ \\
\hline Worldview & $\begin{array}{l}\text { Discharging planning starts on admission so that patients spend the minimum amount of time in the } \\
\text { hospital possible (whilst suitably managing the risk of readmission); this best serves the needs of the } \\
\text { patient and the wider community }\end{array}$ \\
\hline Owner & Discharge Coordinators \\
\hline $\begin{array}{l}\text { Environmental } \\
\text { constraints }\end{array}$ & $\begin{array}{l}\text { Risk of hospital-acquired infections, limited capacity of health and social care practitioners, beds and } \\
\text { funding in the hospital and high demand for treatment from the wider community }\end{array}$ \\
\hline
\end{tabular}

TABLE 9: EXPLORING DIMENSIONS OF 'FLOW' ROOT DEFINITION USING 'CATWOE'

The end state in both the Care model and the Flow model is a patient no longer needing or receiving care within the acute hospital. Discharge is complete when the acute hospital no longer assumes responsibility for the patient's care (which will be ongoing for patients with complex needs).

Note that a given practitioner may subscribe to neither, one or both of these mindsets at different times (we explore this further in the Discussion section). The tension between these viewpoints may frustrate practitioners, supporting a finding of the study by Connelly et al (2009) that staff felt victims of competing pressures, with many solutions beyond their influence. As shown in Figure 2 practitioners must attempt to balance the 'local' need to provide holistic care for the individual on the ward with the wider 'global' responsibility to ensure the service is available and economic for the wider community.



FIGURE 2: HEALTH AND SOCIAL CARE PRACTITIONERS SEEK TO BALANCE PRESSURES IMPLICIT IN THE CARE AND FLOW MODELS 


\section{STAGE 4: CONCEPTUAL MODELS OF RELEVANT SYSTEMS}

For each root definition, a corresponding conceptual model was built, describing the logical sequence of steps that must be followed in order to achieve the transformation as described in the root definition, and identifying the control activities necessary to ensure integrity of the process.

\section{CONCEPTUAL MODEL - CARE}

The conceptual model for the Care philosophy as shown in Figure 3 begins when the patient is medically stable, and focuses on the needs of the individual as they prepare to return home or to a different care setting. In this model, there is a sequential or 'over the wall' mindset to the progress of the patient through the system; once a practitioner is satisfied that the patient has reached the required condition, they are passed on to the next practitioner. In the Care model, the dominant focus is on the health of the patient, with a significant time elapsing between the patient entering the ward and the health needs being dealt with. In this model, planning for the patient's discharge doesn't begin in earnest until a doctor declares the patient medically stable. A number of interactions may then be required with physiotherapists and occupational therapists before the patient is considered functionally ready to leave the acute hospital environment. The patient's destination on discharge from hospital is then considered - either home or to an alternative care setting. If they are going home, the suitability of the home environment needs to be checked. It may be necessary to clean and provide additional equipment such as mobility aids before the home is suitable to accommodate the patient. The final consideration once the home is ready is whether the patient requires support in the community, either from social care or health practitioners. If they do, then a Health Needs Assessment (HNA) form is likely to be needed. As indicated previously, this form may take a long time to complete. When it is finished, Discharge Coordinators can go about finding suitable care in the community, which may itself be a time-consuming process.

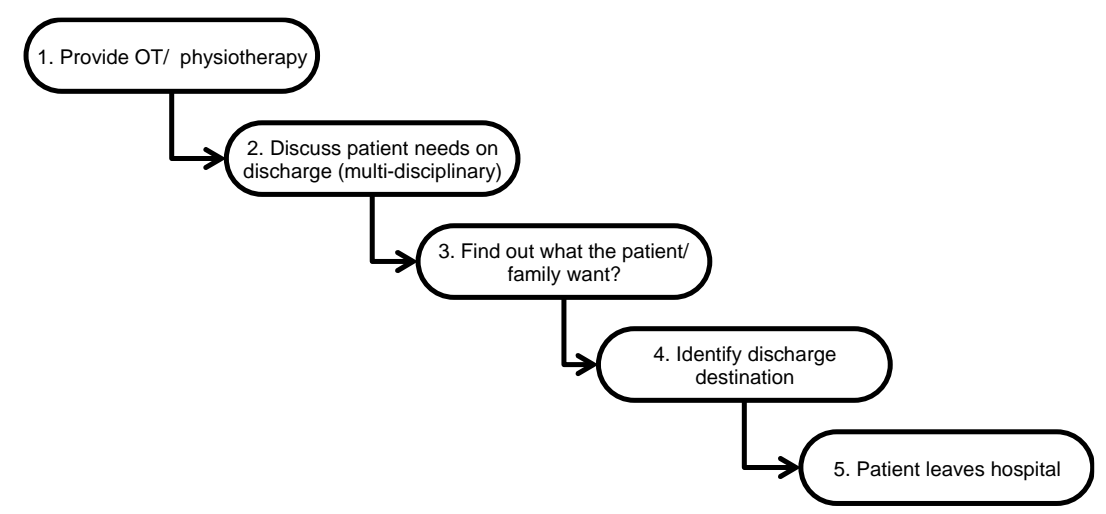

FIGURE 3: CONCEPTUAL MODEL OF THE DISCHARGE PROCESS UNDER THE 'CARE' MODEL

\section{CONCEPTUAL MODEL - FLOW}

In the 'Flow' model there is more proactive preparation for discharge in parallel to a patient's return to health, as shown in Figure 4 - the attitude is similar to a concurrent engineering approach often used in manufacturing and technology development (Nevins \& Whitney, 1989).

The discussion of patient needs (including anticipated social care needs) begins from admission in parallel to the provision of medical treatment and occupational therapy/physiotherapy. Immediately upon arrival on the ward, and on a regular basis afterwards, the question is asked 'can the patient be discharged safely without support?' and, if not, 'can the patient be discharged safely with support?' An estimated discharge date is established and regularly updated, and as the 'health-focused' process of interactions with doctors, nurses and therapists progresses, a 'planning-focused' process begins. This involves talking to the patient and family, investigating the suitability of various discharge destinations, thinking about paperwork necessary for discharge and ultimately ensuring transport and medication that patients will be given to take with them on discharge are available when required. 


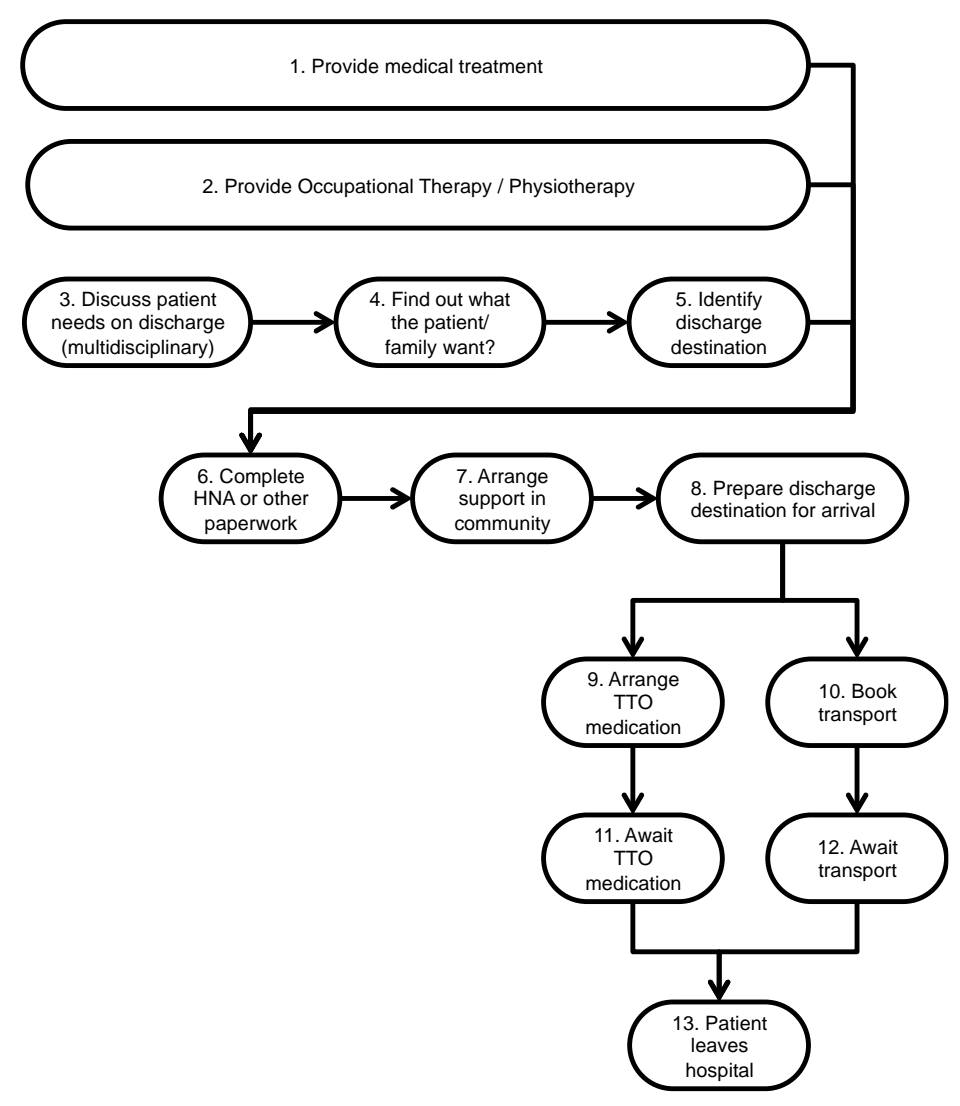

FIGURE 4: CONCEPTUAL MODEL OF THE DISCHARGE PROCESS UNDER THE 'FLOW' MODEL

The key differentiator between the Flow model and the Care model is that the 'health focus' and 'planning focus' steps operate concurrently in the Flow model, whereas in the Care model, the planning focus steps begins only after the health focus steps are completed. Drawing upon the interviews and the common and divergent views analysis, the key differences between the two models are summarised in Table 10.

\begin{tabular}{|c|c|c|}
\hline Theme & Care Model & Flow Model \\
\hline Mindset & $\begin{array}{l}\text { Firefighting - responding to } \\
\text { immediate patient needs }\end{array}$ & Planning - anticipating future patient needs \\
\hline Sequence of interactions & $\begin{array}{l}\text { Serial - ownership of patient care is } \\
\text { managed by a series of different } \\
\text { professionals one at a time }\end{array}$ & $\begin{array}{l}\text { Parallel - several professionals manage the patient's } \\
\text { care concurrently starting their work as soon as } \\
\text { possible }\end{array}$ \\
\hline Indirect patient contact & $\begin{array}{l}\text { Indirect patient contact such as } \\
\text { completion of paperwork is not } \\
\text { urgent }\end{array}$ & $\begin{array}{l}\text { Indirect patient contact including paperwork is } \\
\text { critical to enable an efficient process }\end{array}$ \\
\hline Hospital safety & Patient on ward is safe & $\begin{array}{l}\text { Ward may not be the best place for patient; patient } \\
\text { can contract infections or be injured }\end{array}$ \\
\hline Local vs global needs & $\begin{array}{l}\text { Patient on ward welfare comes first. } \\
\text { Keep patients comfortable on ward } \\
\text { until the transport arrives }\end{array}$ & $\begin{array}{l}\text { Wider population including A\&E patients waiting for } \\
\text { beds should be considered. Send patients to discharge } \\
\text { lounge wherever possible. }\end{array}$ \\
\hline Urgency of discharge & $\begin{array}{l}\text { Discharge when patient is better or } \\
\text { no longer needs hospital care }\end{array}$ & $\begin{array}{l}\text { Discharge early and support patient in the community } \\
\text { or in less expensive locations }\end{array}$ \\
\hline $\begin{array}{l}\text { When to start discharge } \\
\text { planning }\end{array}$ & $\begin{array}{l}\text { Start discharge planning when } \\
\text { patient is medically stable (or first } \\
\text { full MDT meeting) }\end{array}$ & Start discharge planning on admission to hospital \\
\hline Sources of cost & $\begin{array}{l}\text { Readmissions are expensive - must } \\
\text { avoid }\end{array}$ & It is expensive to keep patients in hospital \\
\hline $\begin{array}{l}\text { Which delays to } \\
\text { prioritise }\end{array}$ & $\begin{array}{l}\text { Must avoid delays close to discharge } \\
\text { (after patient is expecting to leave) }\end{array}$ & $\begin{array}{l}\text { Identify and eliminate all delays, including those } \\
\text { before patient is medically stable }\end{array}$ \\
\hline
\end{tabular}

Table 10: Characterising the discharge process in the Care and Flow models 


\section{STAGE 5: COMPARISON OF CONCEPTUAL MODELS WITH THE REAL WORLD}

These conceptual models were then compared with the problem situation and the current practices in the hospital. To validate the conceptual models (and to identify opportunities for actions that could lead to improvements as described in Stage 6 below), the authors conducted a follow-on workshop. This workshop was held with fifteen practitioners and managers to reflect on the findings and to identify the best way to implement any suggested changes. All of the interviewees were invited as well as selected other staff with an interest in discharge planning, but not all of the interviewees were able to attend. The study's preliminary findings were first presented to workshop participants, including Figure 2 and Table 8. Participants were then asked independently to indicate on paper using a five-point scale the extent to which they subscribed to each of the two models (and the implied philosophies). The results are shown in Figure 5 and Figure 6. These results were processed and fed back in real time as part of the workshop.

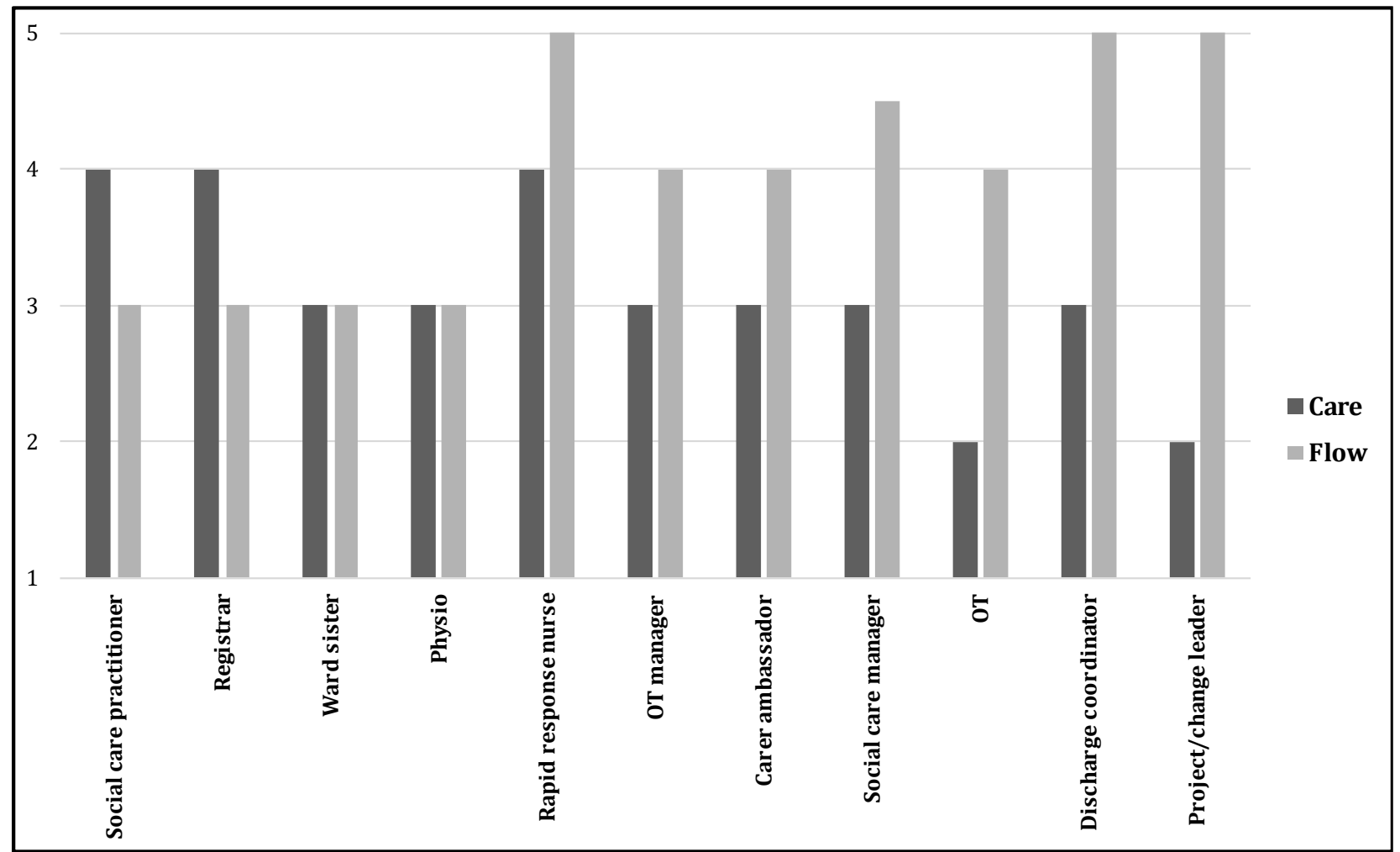

FIGURE 5: HEALTH/SOCIAL CARE PRACTITIONER RESPONSES TO THE QUESTION: 'TO WHAT EXTENT DO YOU FEEL YOU SUBSCRIBE TO THE (A) CARE MODEL, (B) FLOW MODEL' (5 = COMPLETELY, 4 = A LARGE AMOUNT, 3 = A MODERATE AMOUNT, 2 = A SMALL AMOUNT, 1 = NOT AT ALL)

Social Care Practitioners and Doctors recognise the Care model more than the Flow model; Ward Sisters and Physiotherapists see the merits of the two models as roughly equal, and other practitioners favour the Flow model (with Occupational Therapists, Discharge Coordinators and Change Leader roles favouring the Flow model strongly). The mean score for the Care model across all practitioners was 2.9, whilst for the Flow model it was 4.0.

Although there is no formal process for managing the discharge of patients in the hospital, by reflecting on the interview findings and the conceptual models above, the implied logic governing the actual progress of patients can be represented in a process flow diagram (Figure 7). This logic was checked and confirmed to be a fair representation by managers in social care and occupational therapy. Figure 7 captures the essence of both the Care model where focus on patient health prevails and the Flow model, which has a much stronger planning focus. Under the Care model, most of the activities shown in the 'Planning Focus' box occur, but not until the patient has become medically stable and the 'Health Focus' part of the process is complete. In other words, the dotted arrows shown in Figure 7 would not be present in a process flow diagram for the Care model. 


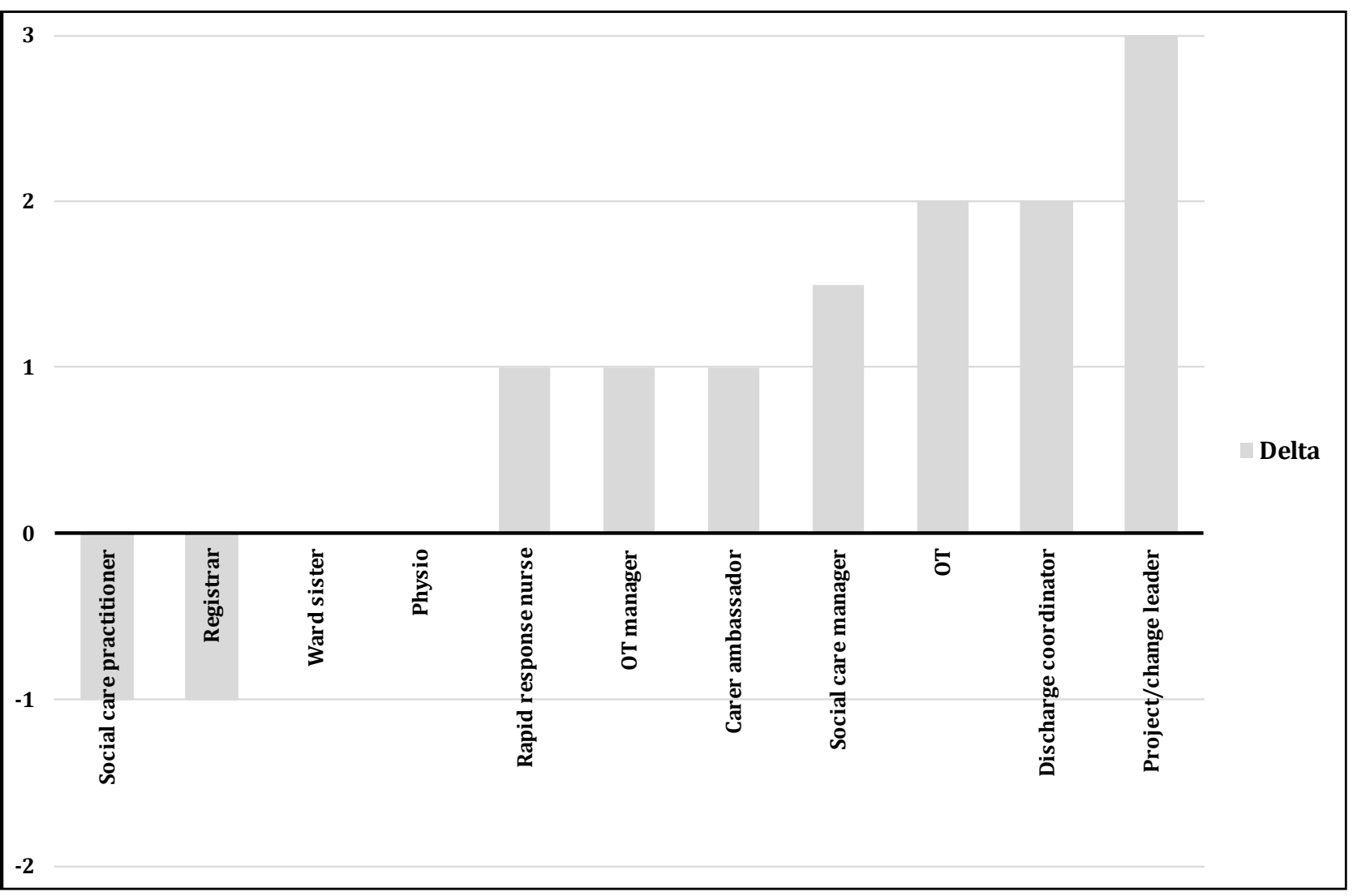

FIGURE 6: DIFFERENCE (FLOW - CARE) BETWEEN FLOW MODEL AND CARE MODEL SCORES BY ROLE

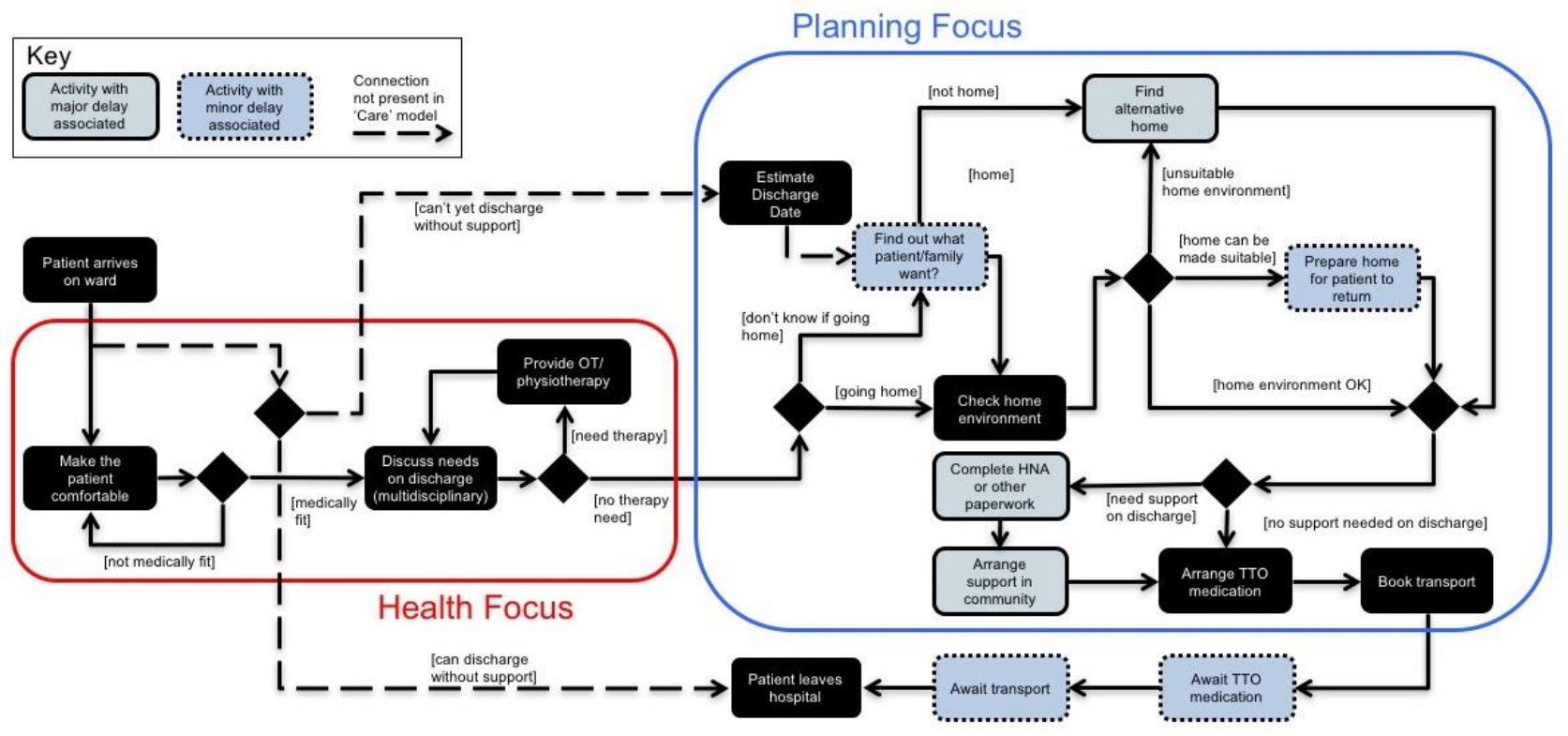

FIGURE 7: PROCESS FLOW DIAGRAM OF THE DISCHARGE PROCESS

\section{RESOURCE CONSTRAINTS}

When contemplating process change based on conceptual modelling, real world resource constraints must be considered. It was clear from the interviews that one of the environmental constraints was the limited availability of funding and staff in the hospital and in social care outside the hospital, reflecting national trends (Care Quality Commission, 2015). If any additional investment was required to improve the effectiveness or efficiency of the discharge process, this would need to be justified fully. 


\section{STAGE 6: IDENTIFY SYSTEMICALLY DESIRABLE AND CULTURALLY FEASIBLE CHANGES}

Having introduced the concepts of Care and Flow and the tension between them, we discussed at the end of the workshop ways in which we could reconcile the competing forces. It was identified that this could be achieved either by removing wasteful processes or by adding extra resources where these were likely to have a particularly high impact.

In the first instance, four practical interventions were identified as summarised in Table 8. These were presented and explored through the workshop. The 'Care' and 'Flow' columns show the extent to which the options align with the corresponding philosophies and the 'Cost' column shows the expected level of additional investment that might be needed to implement the option.

\begin{tabular}{|c|c|c|c|}
\hline Option & Care & Flow & Cost \\
\hline $\begin{array}{l}\text { 1. Super MDT } \\
\text { Daily main MDT meetings. More beds, nurses doctors. }\end{array}$ & ++ & & High \\
\hline $\begin{array}{l}\text { 2. Discharge Planners } \\
\text { Dedicated Discharge Coordinator or 'discharge planner' per ward. More care } \\
\text { in the community. }\end{array}$ & & ++ & High \\
\hline $\begin{array}{l}\text { 3. Communicate } \\
\text { Better communication. Clearer discharge process. }\end{array}$ & + & + & Medium \\
\hline $\begin{array}{l}\text { 4. Proactive } \\
\text { Prioritise paperwork more (especially doctors). Plan further ahead. }\end{array}$ & & + & Low \\
\hline
\end{tabular}

TABLE 11: OPTIONS FOR IMPROVING DISCHARGE PROCESS DEPENDING ON WORLDVIEW AND BUDGET

\section{STAGE 7: TAKE ACTION TO IMPROVE THE PROBLEM SITUATION}

Following the workshop and having gathered feedback on the options presented, there was broad support for the four approaches for improving the discharge process (Table 11), and these influenced the subsequent selection by hospital managers of three practical initiatives that are now underway - 'Front Door', 'Daily Reporting' and 'Removal of HNAs' (shown in Table 12).

\begin{tabular}{|l|l|}
\hline Initiative & Description \\
\hline Front Door & $\begin{array}{l}\text { Recognising patients with social care needs when they are first admitted to hospital and } \\
\text { capturing key information in a single form, so patients are not asked to complete the same } \\
\text { information more than once. }\end{array}$ \\
\hline Daily Reporting & $\begin{array}{l}\text { Ensuring that the needs of patients and any barriers to discharge are discussed daily in a } \\
\text { 'situation report' involving Discharge Coordinators, Social Care Practitioners, health } \\
\text { practitioners (including OTs and Physiotherapists) and community hospital representatives. }\end{array}$ \\
\hline Removal of HNAs & Processing these was identified as a major source of delay. \\
\hline
\end{tabular}

TABLE 12: INITIATIVES UNDERTAKEN BY THE HOSPITAL TO IMPROVE DISCHARGE PLANNING

\section{DISCUSSION}

\section{CARE AND FLOW MODELS}

Table 10 summarises the key differences between the two philosophies. Probably the clearest distinction is the preoccupation in the Care model with the immediate needs of patients on the ward, whereas in the Flow model wider economic and societal needs are considered. Figure 5 shows that practitioners in this study recognised this tension between serving the local and the global needs. All practitioners felt at least a small amount of support for the Care model and a moderate amount of sympathy for the Flow model. Figure 6 shows that the difference in support for the two models is less than one point for 7 out of the 11 roles represented. Figure 6 also reveals that the support for each model varies significantly with role. This is highlighted by the fact that there is a large range from -1 to +3 amongst the various practitioners in the net support for the Flow model relative to the Care model. 
Care and Flow represent different worldviews with each model developed from the interpretation of the problem situation (as expressed in Figure 1) into distinct root definitions and conceptual models. Care and Flow can both be thought of as logical, objective models. As summarised in Table 10, however, the process for taking decisions under the Care mindset may be qualitatively different to decision making under Flow. It seems that the different worldviews typically engage different cognitive processes. In psychology and behavioural economics, dual process theories (DPTs) (Thaler, 2015) are widely recognised for distinguishing between rapid, instinctive decision making, and slower, logical decision making. DPT models are variously framed as Doing vs Planning (Thaler, 1980), Associative vs Rule-based reasoning (Sloman, 1996), System 1 vs System 2 (Stanovich \& West, 2000) and Intuition vs Reasoning (Kahneman, 2003). A classical reference to this decision-making dichotomy was made by Adam Smith in The Theory of Moral Sentiments (Smith, 1790, Ashraf et al., 2005) where he noted the struggle between decisions driven by impulsive 'passions' and those more calculated ones governed by 'the impartial spectator'. The application of DPT in the context of clinical reasoning is an emerging field (Djulbegovic et al., 2012, Marcum, 2012, Islam et al., 2014). Whilst clinical decision making is often assumed to be logic and evidence-driven (Marcum, 2012), fully rational behaviour (in an economic sense) does not come naturally; decision makers are only approximately or 'boundedly' rational in practice (Simon, 1957). It is Care - the personal, compassionate model - that is the natural, trained response for healthcare professionals, that may happen intuitively when rapid decisions are required. It is a serial approach like a classical engineering model seeking to understand fully the performance of the system (the patient's health) from one perspective at a time, addressing the most critical performance drivers first, then handing over responsibility to the next practitioner. It is more like firefighting than high-level, strategic thinking. For this reason, Care has some similarities to System 1 thinking (Stanovich \& West, 2000, Kahneman, 2003) or the heuristic approaches such as the 'Fast and Frugal' algorithms proposed by Gigerenzer and Goldstein (1996), which have been found to be effective in medical decision making (Marewski \& Gigerenzer, 2012). Through firefighting, Care may promote a vicious cycle, however, since a lack of forward planning will lead to greater lengths of stay (there is in fact the implicit assumption that discharging patients too quickly could lead to readmissions which are not only bad for patient care but are also expensive). The Flow model, on the other hand, is like a modern manufacturing mindset focusing on economy and efficiency: it is expensive to keep patients in hospital, so how can we minimise delays and maximise progress? Here, each patient becomes a project and requires a 'project manager' - an individual with responsibility for managing the progress of that patient (this could be the Discharge Coordinator). Like engineering projects, progress should be judged not just in terms of the quality of the outcomes (the wellbeing of the patient), but also in terms of the schedule and the resources consumed. In practice, the Flow model achieves greater throughput not by cutting corners in quality of care, but by undertaking activities in parallel where possible. There is forward planning and parallel identification of problems, including early consideration of paperwork needs alongside medical interventions. Like System 2 thinking (Stanovich \& West, 2000), this requires more time and cognitive effort for healthcare practitioners in the short term; it is not instinctive for doctors and nurses to consider delays, throughput and wider system performance, even though this 'systems' thinking should deliver time savings in the long term by proactively identifying potential barriers to progress.

It is worth noting that despite the apparent greater cognitive challenge of Flow thinking, our workshop participants felt they subscribed to the Flow model more strongly than the Care model. The mean response of 4.0 to the question 'to what extent do you feel you subscribe to the Flow model?' indicated 'a large amount' of support. The mean response of 2.9 to the corresponding question for the Care model indicated they subscribed to Care just less than 'a moderate amount'. It would be interesting to investigate whether the greater reported sympathy for the Flow model is reflected in practitioners' decision making behaviour in practice. Although we have presented the two models as alternatives, it seems likely that Care and Flow will in practice influence decisions in tandem, such as in Mukherjee's model of decision making under uncertainty as a weighted combination of System 1 and System 2 thinking (Mukherjee, 2010). Indeed, although previous studies have reported that rapid, intuitive, heuristic based-decision making (System 1) may be more prone to cognitive errors than the slower, rational decision making (System 2) (Hammond et al., 1998), more recent studies in clinical decision making have found System 1 to be no more prone to error than System 2, and that a combination of both strategies can lead to reduced error rates in diagnosis (Norman, 2009). 


\section{REFLECTIONS ON SSM PROCESS}

The development of conceptual models is a logical process - it is an account of the activities which the system must do in order to be the system named in the root definition. Two conceptual models seemed to be a natural number for the SSM process. It proved sufficient to explore a range of different issues and to identify the key tensions; a larger number would have been more time consuming to develop and difficult to communicate. Whilst some recent studies have preferred the four-stage process for SSM (Kotiadis et al., 2013), the seven-stage process for SSM was intuitive and readily applicable to the problem situation investigated.

The PQR summary of the root definitions as shown in Table 6 and Table 8 proved very useful to clarify our thinking about the different models and their corresponding worldviews. The transformation (the 'do P' expression in the PQR) captured the essence of each model and is worthy of further scrutiny. For Care, the transformation is to 'enable medically stable patients to leave the acute hospital environment'. Enable patients to leave suggests that the process is a gate-keeping function that ensures that patients can only leave when they are ready to leave. Note also that medically stable patients are the focus of this process. This reinforces the idea that in the Care model discharge is not about planning ahead - discharge planning has no significance until the patient is medically stable. Implicit in this model is the idea that the acute hospital is a safe environment for patients until they are medically stable. In the Flow model, 'prepare patients admitted to the hospital for timely release from acute care' has three important aspects. Firstly, prepare, suggests the emphasis is on planning ahead rather than the gate keeping of Care. Secondly, the customers of the process are patients admitted to hospital. Planning starts on admission so is very forward looking. Finally, there is an explicit focus in the PQR on timely release - minimising time taken is an objective of the process. There is no reference to time in the Care model, just as there is no reference to quality of care in the Flow model. Drawing out the PQR through the SSM process made this distinction clear and helped to clarify our thinking about the different underlying worldviews and the tensions felt by practitioners.

When developing worldviews, we first attempting to express these 'organically' without constraining them to fit any particular pattern. We then used the W1 (How) and W2 (Why) approach explained in Table 2 to check whether the root definitions made sense. Going through this process enabled us to improve our understanding of the transformation. For example, Table 13 shows these worldview variants for the Care model. This exercise highlighted the fact that in the Care model there is explicit concern about those barriers to discharge at the back end of the process such as awaiting transport and medication to take out. In the Flow model these are not emphasised, since they cause minor delays relative to paperwork and arranging support in the community (as shown in Figure 7).

W: Keeping the patient in the safe hospital environment and starting discharge planning only when the patient is medically stable avoids wasted practitioner time (since the patient's condition may change) and minimises the risk of readmission

W1 (How?): Completing relevant paperwork and arranging transport, medication to take out and any necessary care in the community, whilst providing ongoing care from medical practitioners, is an effective and efficient way to enable medically stable patients to leave the acute hospital environment when they are ready to go

W2 (Why?) Enabling medically stable patients to leave the acute hospital environment when they are ready to go is an effective and efficient way to ensure that patients on the wards receive the best possible care up to and beyond discharge from the acute hospital

TABLE 13: USING WORLDVIEWS TO CHECK CARE ROOT DEFINITION

Because we identified the value of applying SSM for the study before we started the interviews, we were able to structure the interview questions to ensure that the aspects relevant for SSM were captured (in particular the CATWOE elements and the ideas of effectiveness and efficiency of the process). This was not done by Mukotekwa and Carson, who generally used open-ended questions such as 'how far are you towards getting Mr A discharged' (Mukotekwa \& Carson, 2007: 672). Including the CATWOE elements ensured that the root definitions were comprehensive, but it made the single sentence description of the root definition very long. We found the PQR tables (Table 6 and Table 8) and the CATWOE tables (Table 7 and Table 9) more useful for discussion than the single long sentence expression of the root definition. Using the workshop to validate the two root definitions 
and the tension between them before developing concrete recommendations worked well. Not only did it give us confidence that we had developed something relevant to the practitioner community, it also helped achieve buyin to the process and for the interventions to follow.

The Care and Flow models developed here echo aspects of the 'Seamless service provision' and 'Effective resource utilisation' models developed by (Mukotekwa \& Carson, 2007). A significant difference between our approach and the approach adopted by Mukotekwa and Carson, however, was in the framing of the transformations. We started the investigation with the premise that patients were spending longer on wards than was necessary, and used SSM as a lens to try to improve our understanding of current attitudes in the system. We did not frame our root definitions in terms of ways in which the process could be improved. In both the Care model and the Flow model, we took patients to be the physical inputs and outputs (in different states) of the process. Mukotekwa and Carson, on the other hand, focused on two different views on how to improve the discharge process focusing on two concerns that emerged from their interviews. In Seamless Service Provision, the abstract transformation was from a process with ineffective continuity of care to one with effective continuity of care. In Effective Resource Utilisation, the change was again abstract, from a process with ineffective utilisation of resources to one with effective utilisation of resources. Both a strength and a challenge of SSM is its subjectivity and flexibility. Although there are some rules that govern the proper formulation of root definitions, such as the input and output of the transformation must be of the same kind - either physical or abstract (Wilson, 2001), there is no single right way of modelling a problem situation. Different approaches lead to different insights.

\section{CONCLUSIONS}

Through the use of a soft systems approach (SSM) including a series of twenty structured interviews, we have been able to gain insights into why discharge planning in acute hospitals is so difficult. Various problems with the process have been identified, including in particular ineffective communication, slow processing of paperwork, limited forward planning, a lack of ownership of the process and a lack of availability of care in the community.

We have identified two competing philosophies within hospitals - a traditional 'Care' model focusing on the immediate needs of patients on the wards (local view), and a planning-focused 'Flow' model, where the hospital's responsibility to the wider community dominates (global view). Both of these philosophies were seen to be relevant by all of the practitioners interviewed in this project. Whilst recognition of the two mindsets varied across practitioner types (as shown in Figure 5 and Figure 6), practitioners reported a significantly greater support for the Flow model than the Care model. There was a mean level of support of 4.0 out of 5 for Flow (indicating on average 'a large amount' of support), compared to 2.9 out of 5 for Care ('a moderate amount' of support). What this greater support for the Flow model means in practice is not yet understood. Do healthcare practitioners simply feel that they should be thinking more in terms of Flow with its planning ahead and strategic thinking in order to improve process efficiency, or do they actually think this way? In other words, do the Care and Flow models describe just attitudes, or also behaviour? Our impression from the interviews is that Care is the dominant model of behaviour for many practitioners. Since discharge needs several practitioners to approve the decision to discharge each patient (mostly through multi-disciplinary team meetings), if any practitioner's behaviour reflects the less proactive Care model, the patient's progress may be delayed. A clear example of this is where time-consuming paperwork necessary before discharge is not prioritised by doctors until patients are medically stable.

The selection of SSM rather than a quantitative modelling approach meant that only general insights into the process could be obtained rather than reliable statistical data. SSM was found to be an appropriate tool for this purpose, though, and proved very effective for handling the multiple viewpoints encountered. Not least in facilitating access to this wide pool of practitioners, it proved extremely useful to have buy-in for the study from key managers in the hospital. By focusing on two care of the elderly wards we were able to interview a high proportion of the relevant practitioners on these wards across many different roles. However, whilst we performed interviews with a Registrar and several Consultants, it was disappointing that no junior doctors 
responded to our request to be interviewed. In the absence of this data, we inferred the view of junior doctors from comments made by other interviewees. The study took place in a single acute hospital in Surrey, UK, and it is not yet known to what extent the findings of this study are specific to the hospital. Comparison with previous studies suggests that many of the same views may be held by practitioners elsewhere. Indeed, several of the staff interviewed have held positions in other UK hospitals and indicated that experiences elsewhere were similar to those described here. Further research is needed, however, to understand the extent to which the differences of perception described here are shared elsewhere and whether they are truly hampering attempts to improve the discharge planning process.

Further studies are also needed to understand how Care and Flow thinking is manifested in actual decision situations. Within a DPT context, we should investigate whether Care and Flow both feature in logical decision making (System 2), or whether Care tends to reflect intuition (System 1) and Flow represents reasoning (System 2). Are practitioners under the influence of just one of these mindsets at a time, or do both models operate in parallel? It would also be useful to explore how the influence of the two models varies with the time available to make decisions; if Flow thinking is stifled by time pressures, can decision-making aids be developed to promote Flow thinking under time constraints? The high complexity of healthcare decision making is well known; Gawande has written of the value of checklists in improving performance in these situations (Gawande, 2011). Whilst checklists are already used in the hospital for decision making regarding discharge, however, they apply only for part of the process and for a small subset of patients with a particular set of social care needs. A checklist for the whole discharge process would be a valuable decision aid, although it would itself need to be quite sophisticated to cover the range of circumstances encountered in the patient journey.

Failure to acknowledge and manage the tension between the Care and Flow philosophies may explain why problems with discharge planning persist despite the fact that legislation and recommendations on discharge planning have been offered since at least 1990 (National Health Service and Community Care Act, 1990). The tension is likely to increase as the proportion of patients presenting with complex needs rises with the ageing population (NHS, 2014). By recognising the tension in this project, we have been able to identify a number of means of reconciling the conflicting demands, in particular through avoiding wasteful processes and by deploying additional resources where they have the greatest leverage. This should mean that better quality care can be delivered without delaying discharge. Alternatively, it should be possible for the efficiency of the discharge process to improve without worsening the quality of care. With this in mind, three practical recommendations for improving discharge planning have now been implemented in the hospital: (i) more proactive identification at the hospital front door of patients with complex needs (ii) daily situation reports to discuss patient progress involving a multi-disciplinary team with clear leadership, and (iii) simplifying the paperwork necessary before patients with complex needs can be discharged. These three initiatives are consistent with the three general themes presented in Table 1 that were abstracted from the UK Department of Health guidance (Department of Health, 2010). Firstly, more proactive identification at the front door of patients with complex needs aligns closely with the Table 1 theme of 'proactivity' (with its focus on planning for discharge starting on or before admission and early identification of patients with complex needs). Secondly, our recommendation of daily situation reports to discuss patient progress involving a multi-disciplinary team with clear leadership maps to the 'effective communication' theme (which stresses effective leadership and handover of responsibilities and a clinical management plan reviewed with the patient and carers each day). Finally, simplifying the paperwork necessary before patients with complex needs can be discharged can be considered sympathetic to the theme of 'keeping the process moving', which emphasises amongst other things the value of simple paperwork. The three initiatives proposed in this project have been implemented and are being monitored. Initial findings are very encouraging and will be reported in a subsequent publication. 


\section{ACKNOWLEDGEMENTS}

The authors are grateful for the time given up by the interviewees at the hospital.

This project was undertaken as part of a lean green belt initiative supported by Patients First (a major transformation programme established in May 2008 to use tools such as lean and Six Sigma to deliver improved patient care). At the time of the project, one of the authors (S. Smith) was working in the Adult Social Care team at Surrey County Council, Kingston Upon Thames, UK.

\section{APPENDIX}

\section{QUESTIONS ASKED OF INTERVIEWEES}

The following questions were asked of the interviewees.

1. What are the steps involved in the current discharge process?

2. When does the discharge process start and end?

3. Who implements the discharge process? Does anyone have overall responsibility for managing the discharge of an individual patient?

4. Who owns the discharge process (with the authority to redefine the process for all patients)?

5. Who are the beneficiaries of the discharge process?

6. What is the purpose of the discharge process - what is it supposed to achieve?

7. What external factors constrain the discharge process?

8. How effective is the discharge process? What does effectiveness mean?

9. How efficient is the discharge process? What does efficiency mean?

\section{REFERENCES}

ASHRAF, N, CAMERER, C F and LOEWENSTEIN, G (2005) Adam Smith, Behavioral Economist. Journal of Economic Perspectives, 19, 131-145.

ATWAL, A (2002) Nurses' perceptions of discharge planning in acute health care: a case study in one British teaching hospital. Issues and Innovations in Nursing Practice, 39, 450-458.

AUDIT COMMISSION (2002) Integrated services for older people: building a whole system approach in England.

BALDWIN, L P, ELDABI, T and PAUL, R J (2004) Simulation in healthcare management: a soft approach. Simulation Modelling Practice and Theory, 12, 541-557.

BAUER, M, FITZGERALD, L, HAESLER, E and MANFRIN, M (2009) Hospital discharge planning for frail older people and their family. Are we delivering best practice? A review of the evidence. Journal of Clinical Nursing, 18, 2539-2546.

BRAILSFORD, S C, LATTIMER, V A, TARNARAS, P and TURNBULL, J C (2004) Emergency and on-demand health care: Modelling a large complex system. Journal of the Operational Research Society, 55, 34-42.

BULL, M J (1994) Patients' and professionals' perceptions of quality in discharge planning. Journal of Nursing Care Quality, 8, 47-61.

BULL, M J and ROBERTS, J (2001) Components of a proper hospital discharge for elders. Journal of Advanced Nursing, 35, 571-581.

CARE QUALITY COMMISSION (2015) The state of health care and adult social care in England 2014/15.

CHECKLAND, P (1999) Systems Thinking, Systems Practice, Chichester, Wiley.

CHECKLAND, P (2012) Four Conditions for Serious Systems Thinking and Action. Systems Research and Behavioural Science, 29, 465-469.

CHECKLAND, P and POULTER, J (1994) Application of soft systems methodology to the production of a hospital information and systems strategy. United Kingdom: HISS Central Team of the NHS Management Executive.

CHECKLAND, P and POUlTER, J (2006) Learning for Action: A Short Definitive Account of Soft Systems Methodology and its use for Practitioners, Teachers and Students, Chichester, Wiley.

CHECKLAND, P and SCHOLES, J (1999) Soft Systems Methodology in Action, Chichester, Wiley.

CONNELLY, M, GRIMSHAW, J, DODD, M, CAWTHORNE, J, HULME, T, EVERITT, S, TIERNEY, S and DEATON, C (2009) Systems and people under pressure: the discharge process in an acute hospital. Journal of Clinical Nursing, 18, 549-558. 
CRESWELL (2014) Research Design: Qualitative, Quantitative, and Mixed Methods Approaches, London, SAGE Publications.

CUMMINGS, C and COCKERHAM, C (1997) Ethical dilemmas in discharge planning for patients with Alzheimer's disease. Health and Social Work, 22, 101-108.

CUMMINGS, S (1999) Adequacy of discharge plans and rehospitalisation among hospitalised dementia patients. Health and Social Work, 24, 249-259.

DEPARTMENT OF HEALTH (2003) Discharge from hospital: Pathway, process and practice.

DEPARTMENT OF HEALTH (2004) Achieving timely 'simple' discharge from hospital.

DEPARTMENT OF HEALTH (2010) Ready to go? Planning the discharge and the transfer of patients from hospital and intermediate care.

DJULBEGOVIC, B, HOZO, I, BECKSTEAD, J, TSALATSANIS, A and PAUKER, S G (2012) Dual processing model of medical decision-making. BMC Medical Informatics and Decision Making, 12, 1-13.

EDEN, C (1989) Using cognitive mapping for strategic options development and analysis (SODA). In: ROSENHEAD, J (ed.) Rational Analysis for a Problematic World: Problem Structuring Methods for Complexity, Uncertainty and Conflict. Chichester UK: John Wiley and Sons.

EL-DARZI, E, VASILAKIS, C, CHAUSSALET, T and MILLARD, P H (1998) A simulation modelling approach to evaluating length of stay, occupancy, emptiness and bed blocking in a hospital geriatric department. Health Care Management Science, 1, 143-149.

EMES, M R, BRYANT, P A, WILKINSON, M K, KING, P, JAMES, A M and ARNOLD, S (2012) Interpreting 'Systems Architecting'. Systems Engineering, 15, 369-395.

ESAIN, A E, WILLIAMS, S J, GAKHAL, S, CALEY, L and COOKE, M W (2012) Healthcare quality improvement policy implications and practicalities. International Journal of Health Care Quality Assurance, 25, 565581.

FOUST, J B (2007) Discharge planning as part of daily nursing practice. Applied Nursing Research, 20, 72-77.

FRIEND, J K and HICKLING, A (1987) Planning Under Pressure, Chichester UK, John Wiley and Sons.

GAWANDE, A (2011) The Checklist Manifesto, London, Profile books.

GIGERENZER, G and GOLDSTEIN, D G (1996) Reasoning the Fast and Frugal Way: Models of Bounded Rationality. Psychological Review, 103, 650-669.

GODFREY, M and TOWNSEND, J (2009) Delayed Hospital Discharge in England and Scotland: A Comparative Study of Policy and Implementation. Journal of Integrated Care, 17, 26-36.

GONÇALVES-BRADLEY, D, LANNIN, N, CLEMSON, L, CAMERON, I and SHEPPERD, S (2016) Discharge planning from hospital (Review). Cochrane Database of Systematic Reviews.

GUNAL, M M (2012) A guide for building hospital simulation models. Health Systems, 1, 17-25.

HAMMOND, J S, KEENEY, R L and RAIFFA, H (1998) The hidden traps in decision making. Harvard Business Review, 76, 47-48.

HEALTH \& SOCIAL CARE JOINT UNIT AND CHANGE AGENTS TEAM (2003) Discharge from hospital: pathway, process and practice. Department of Health.

ISLAM, R, WEIR, C and DEL FIOL, G (2014) Heuristics in Managing Complex Clinical Decision Tasks in Experts' Decision Making. IEEE Int Conf Heathc Inform., 186-193.

JACKSON, M (2000) Systems Approaches to Management, New York, Kluwer.

KABA, A, WISHART, I, FRASER, K, CODERRE, S and MCLAUGHLIN, K (2016) Are we at risk of groupthink in our approach to teamwork interventions in health care? Medical Education, 50, 400-408.

KAHNEMAN, D (2003) A perspective on judgment and choice: Mapping Bounded Rationality. American Psychologist, 58, 697-720.

KALIM, K, CARSON, E and CRAMP, D (2004) The role of soft systems methodology in healthcare policy provision and decision support. IEEE International Conference on Systems, Man and Cybernetics. The Hague, Netherlands.

KATSALIAKI, K, BRAILSFORD, S, BROWNING, D and KNIGHT, P (2005) Mapping care pathways for the elderly. Journal of Health Organization and Management, 19, 57-72.

KHURMA, N. (2009) Analysis, Modeling and Improvement of Patient Discharge Process in a Regional Hospital. Master of Applied Science, University of Windsor.

KHURMA, N, SALAMATI, F and PASEK, Z J. Simulation of patient discharge process and its improvement. In: PASUPATHY, R, KIM, S H, TOLK, A, HILL, R and KUHL, M E, eds. Winter Simulation Conference, 2013 Washington DC. IEEE.

KOTIADIS, K, TAKO, A A, ROUWETTE, E A J A, VASILAKIS, C, BRENNAN, J, GANDHI, P, WEGSTAPEL, H, SAGIAS, F and WEBB, P (2013) Using a model of the performance measures in Soft Systems Methodology (SSM) to take action: a case study in health care. Journal of the Operational Research Society, 64, 125-137.

KOTIADIS, K, TAKO, A A and VASILAKIS, C (2014) A Participative and Facilitative Conceptual Modelling Framework for Discrete Event Simulation Studies in Healthcare. Journal of the Operational Research Society, 65, 197-213. 
LATTIMER, V, BRAILSFORD, S, TURNBULL, J, TARNARAS, P, SMITH, H, GEORGE, S, GERARD, K and MASLINPROTHERO, S (2004) Reviewing emergency care systems I: insights from system dynamics modelling. Emergency Medicine Journal, 21, 685-691.

LEHANEY, B and PAUL, R J (1996) The Use of Soft Systems Methodology in the Development of a Simulation of Out-patient Services at Watford General Hospital. Journal of the Operational Research Society, 47, 864870.

MARAMBA, P, RICHARDS, S and LARRABEE, J (2004) Discharge planning process: applying a model for evidencebased practice. Journal of Nursing Care Quality, 19, 123-129.

MARCUM, J A (2012) An integrated model of clinical reasoning: dual-process theory of cognition and metacognition. Journal of Evaluation in Clinical Practice, 18, 954-961.

MAREWSKI, J N and GIGERENZER, G (2012) Heuristic decision making in medicine. Dialogues in Clinical Neuroscience, 14, 77-89.

MILLARD, P H. (1993) Flow rate modelling: A method of comparing performance in departments of geriatric medicine. University of London.

MILLARD, P H, MACKAY, M, VASILAKIS, C and CHRISTODOULOU, G (2000) Measuring and modelling surgical bed usage. Annals of the Royal College of Surgeons of England, 82, 75-82.

MUKHERJEE, K (2010) A Dual System Model of Preferences Under Risk. Psychological Review, 117, $243-255$.

MUKOTEKWA, C and CARSON, E (2007) Improving the discharge planning process: a systems study. Journal of Research in Nursing, 12, 667-686.

NATIONAL AUDIT OFFICE (2003) Ensuring the effective discharge of older patients from NHS acute hospitals. London: The Stationery Office.

NATIONAL HEALTH SERVICE AND COMMUNITY CARE ACT (1990) Chapter 19. London: The Stationery Office.

NAYLOR, M D, BROOTEN, D, CAMPBELL, R, JACOBSEN, B S, MEZEY, M D, PAULY, M V and SCHWARTZ, J S (1999) Comprehensive discharge planning and home follow-up of hospitalized elders. Journal of the Americal Medical Association, 281, 613-620.

NEVINS, J L and WHITNEY, D E (1989) Concurrent Design of Products and Processes: A Strategy for the Next Generation in Manufacturing, New York, McGraw-Hill.

NHS. (2014) The NHS belongs to the people: a call to action. Available: http://www.nhs.uk/NHSEngland/thenhs/about/Documents/nhs-belongs-to-the-people-call-toaction.pdf.

NORMAN, G (2009) Dual processing and diagnostic errors. Advances in Health Sciences Education, 14, 37-49.

PAYNE, S, KERR, C, HAWKER, S, HARDEY, M and POWELL, J (2002) The communication of information about older people and social care practitioners. Age and Ageing, 31.

ROSE, J and HAYNES, M (1999) A Soft Systems Approach to the Evaluation of Complex Interventions in the Public Sector. Journal of Applied Management Studies, 8, 199-216.

ROSENHEAD, J (1996) What's the Problem? An Introduction to Problem Structuring Methods. Interfaces, 26, 117131.

SALAS, E, DIAZGRANADOS, D, KLEIN, C, BURKE, C S, STAGL, K C, GOODWIN, G F and HALPIN, S M (2008) Does Team Training Improve Team Performance? A Meta-Analysis. Human Factors, 50, 903-933.

SHEPPERD, S, LANNIN, N A, CLEMSON, L M, MCCLUSKEY, A, CAMERON, I D and BARRAS, S L (2003) Discharge planning from hospital to home. Cochrane Database of Systematic Reviews.

SIMON (1957) Models of Man, New York, Wiley.

SLOMAN, S A (1996) The empirical case for two systems of reasoning. Psychological Bulletin, 3-22.

SMITH, A (1790) The Theory of Moral Sentiments, London, A. Millar.

STANOVICH, K E and WEST, R F (2000) Individual differences in reasoning: Implications for the rationality debate? Behavioral and Brain Sciences, 23, 645-726.

TARABORRELli, P, WOOD, F, PITHOUSE, A, BLOOR, M and PARRY, O (1998) Hospital Discharge for Frail Older People: A Literature Review with Practice Case Studies. Social Work Research Findings. The Scottish Office Central Research Unit.

THALER, R H (1980) Toward a positive theory of consumer choice. Journal of Economic Behavior and Organization, 1, 39-60.

THALER, R H (2015) Misbehaving: The making of behavioural economics, Allen Lane.

WATTS, R and GARDNER, H (2005) Nurses' perceptions of discharge planning. Nursing and Health Sciences, 7 , 175-183.

WELLS, J (1995) Discontent without focus? An analysis of nurse management and activity on a psychiatric inpatient facility using a 'soft systems' approach. Journal of Advanced Nursing, 21, 214-221.

WHO (2009) Systems Thinking for Health Systems Strengthening. In: DE SAVIGNY, D and TAGHREED, A (eds.). World Health Organisation and Alliance for Health Policy and Systems Research.

WILSON, B (2001) Soft Systems Methodology: Conceptual Model Building and its Contribution, Chichester, John Wiley \& Sons Ltd. 